\title{
AS RELAÇÕES DE GÊNERO NA OPÇÃO DE LAZER DE PESSOAS ATUANTES EM COOPERATIVAS DE TRABALHO
}

Recebido em: $21 / 05 / 2013$

Aceito em: 20/07/2013

\author{
Daniel Bidia Olmedo Tejera ${ }^{1}$ \\ Universidade Estadual Paulista "Júlio de Mesquita Filho \\ Rio Claro - São Paulo - Brasil \\ Ioranny Raquel Castro de Sousa ${ }^{2}$ \\ Tânia Mara Vieira Sampaio ${ }^{3}$ \\ Universidade Católica de Brasília \\ Brasília - DF - Brasil
}

RESUMO: A pesquisa trata das relações de gênero na experiência de lazer de um grupo de participantes de cooperativas de trabalho. O objetivo do estudo foi identificar a diferença entre atividades de lazer vividas pelas mulheres e homens trabalhadores de Cooperativas e as relações de gênero entremeadas nos principais conteúdos culturais do lazer que aparecem em suas práticas. Esta é uma pesquisa qualitativa e exploratória, na metodologia usou-se a combinação de pesquisa bibliográfica e de campo. Participaram 45 cooperados de 4 cooperativas. Os resultados evidenciaram que a categoria de gênero proporciona muitas possibilidades de análise sobre os processos de naturalização das relações sociais e que as mulheres efetivamente possuem mais dificuldade em desfrutar do tempo livre do que homens.

PALAVRAS CHAVE: Atividades de Lazer. Identidade de Gênero.

\section{GENDER RELATIONS IN THE COOPERATIVE WORKER'S LEISURE OPTION}

ABSTRACT: This research deals with gender relations in leisure experience enjoyed by a group of Cooperative workers. The study aimed at identifying the differences between leisure activities experienced by women and men Cooperative workers and gender relations, basing the analysis in the cultural content of these leisure practices. This is a qualitative exploratory study. The methodology used is a combination of

\footnotetext{
${ }^{1}$ Mestre pelo DEF/IB Universidade Estadual Paulista Júlio de Mesquita Filho - Rio Claro/SP - Bolsista $\mathrm{CNPq}$ / Integrante do GPL.

${ }^{2}$ Licenciada e Bacharelada em Educação Física e Mestranda em Educação Física pela Universidade Católica de Brasília - UCB.

${ }^{3}$ Doutora em Ciências da Religião. Docente dos Cursos de Graduação e Pós-Graduação Stricto Sensu (Mestrado e Doutorado) em Educação Física da Universidade Católica de Brasília - UCB.
} 
literary research and field research. Participated in Fourty five members of four cooperatives were. The results showed that gender category provides many different analysis possibilities about the naturalization process of social relations, and the fact that women have more difficulty enjoying free time than men.

KEYWORDS: Leisure Activities. Gender Identity.

\section{INTRODUÇÃO}

Os momentos livres das obrigações podem ser vivenciados como tempo de lazer ou não e nestes sabemos que ocorrem processos relacionais de gênero que são fruto de construções históricas e culturais. Um grupo de homens e mulheres, participantes de quatro cooperativas de trabalho de Piracicaba-SP, tornou-se sujeito de nossas interrogações acerca das relações de gênero na experiência de lazer que vivenciam.

O conjunto de concepções que determinada cultura estabelece sobre o feminino e o masculino, são fruto de construção social e cultural e marcam fortemente a história da humanidade. Essa construção denominada "relações de gênero" implica em relações sociais de poder entre homens e mulheres e criam nas sociedades determinadas expectativas para o comportamento do homem e da mulher.

Gênero também é o conjunto de expressões daquilo que se pensa sobre o masculino e o feminino. Ou seja, a sociedade constrói longamente, durante os séculos de sua história, significados, símbolos e características para interpretar cada um dos sexos. A essa construção social dá-se o nome de "relações de gênero". Por causa do modo como as pessoas percebem os gêneros, masculino e feminino, na sociedade é que se espera uma série de coisas tanto dos homens quanto das mulheres (AUAD, 2003, p.57).

Os fatores sociais determinam as expectativas de uma pessoa em relação a um ou mais indivíduos, ou a um grupo todo. Dentro de diversas culturas espera-se um determinado comportamento daqueles que nascem com uma anatomia do sexo masculino, bem como do feminino. Os pais socializam e educam seus filhos de maneira diferente de acordo com o sexo, desde o nascimento, o que inevitavelmente irá proporcionar diferentes tipos de experiências (SAMPAIO, 2009). A influência de pais e 
professores sobre as crianças será determinante em muitos aspectos, dependendo do conceito de masculinidade e feminilidade que estes possuem, conforme se pode observar nos estudos de Guacira Louro, (1997); Raquel Siebert (1995); Patrícia Vieira et al, (1995); Priscila Gomes (2012); Raquel Gonçalves (2012). Em síntese, pode-se afirmar que as crianças desde cedo, são ensinadas de acordo com seu sexo, a serem "homem" ou "mulher".

Esta concepção também é apontada por Eustáquia de Sousa e Helena Altmann, (1999) ao reforçarem que a forma de se educar homens e mulheres presume uma construção social e corporal implicando diretamente no processo de ensinoaprendizagem de valores como conhecimentos, costumes e gestos corporais tidos como masculinos ou femininos.

Sabendo então da persuasão dos pais e mães, professoras e professores na construção da concepção de gênero de seus respectivos filhos(as) e alunos(as), e da influência no comportamento humano, não seria diferente encontrá-las nas especificidades do Lazer.

Contudo, para que seja possível uma democratização cultural, isto é um amplo acesso ao Lazer, é preciso que vários fatores contribuam para a superação das práticas conformistas, alienadas e manipuladas por um conjunto social no qual as relações de poder inferiorizam as pessoas impedindo-as de vivenciarem seus direitos fundamentais para sua constituição de ser no mundo. Uma experiência de Lazer em níveis críticos e criativos pode oportunizar a homens e mulheres caminhos de transformação e re-significação cultural das representações sociais esperadas para ambos os sexos (SAMPAIO, 2008, p. 140).

Nelson Marcellino (2002) refere-se ao lazer como uma esfera social importante na vida moderna para mudanças de ordem moral e cultural. Ele ainda complementa que ao contrário do comportamento de grande parte das pessoas, o lazer não deve ser tido como um assimilador de tensões ou uma atividade compensatória de uma rotina estafante. Os interesses buscados no lazer podem ser classificados em sete vertentes 
principais, denominadas “conteúdos culturais do lazer”, a saber: interesses artísticos, intelectuais, físico-esportivos, manuais e sociais, estabelecidos pelo sociólogo francês Joffre Dumazedier (1980), mais o conteúdo turístico inserido posteriormente por Luiz Otávio Camargo (1992) e também o interesse virtual postulado por Gisele Schwartz (2003).

Magnani (2000), por sua vez, sintetiza o lazer como um conjunto determinado de atividades de caráter individual ou coletivo, na perspectiva de buscar a satisfação por meio de diversos tipos de interesses ligados a criatividade, formação e desenvolvimento pessoal, descanso, divertimento etc. São estas atividades realizadas no tempo livre das obrigações, tanto do trabalho como de qualquer outro tipo de obrigação social.

Para Marcellino (2002) para que um momento de lazer possa ser caracterizado como tal, é necessário que este contenha os aspectos "tempo" e "atitude" de maneira integrada. O primeiro aspecto refere-se ao tempo livre do trabalho e qualquer outro tipo de obrigação, portanto, um tempo disponível para o lazer, já o segundo aspecto é referente à atitude e liberdade de escolha da atividade que se deseja realizar, simplesmente em busca do prazer em realizá-la.

\footnotetext{
Poucas sociedades humanas existem, se e que existe alguma, que não possuam um equivalente às nossas atividades de lazer, que não tenham danças, confrontos simulados, exibições acrobáticas ou musicais, cerimônias de invocação dos espíritos - em resumo, sem instituições sociais que proporcionam, por assim dizer, a renovação emocional por meio do equilíbrio entre os esforços e as pressões da vida ordinária, com as suas lutas a sério, os perigos, os riscos e os seus constrangimentos (ELIAS; DUNNING, 1985, p.73).
}

Considerando que as atividades lúdicas ou de lazer integram a vida cotidiana das pessoas, o aspecto relativo à diferenciação na escolha das atividades praticadas por homens e mulheres tende a estar marcada por fatores culturais e sociais, apresentando muitas vezes os homens buscando a prática de atividades de interesse físico esportivo e 
as mulheres a prática de atividades de cunho artístico e social (SILVA; SOUSA; SAMPAIO, 2012).

As análises de gênero permitem apresentar o acesso diferenciado por meio dos quais homens e mulheres experimentam o lazer, possibilitando que ambos desfrutem deste em níveis críticos, transformando e re-significando a cultura existente. Dessa forma, se poderia re-inventar as relações cotidianas, principalmente frente ao lazer, e desmitificar que o gênero feminino e outros grupos sociais, como negros e indígenas, devem subordinar-se ao gênero masculino.

\begin{abstract}
A concepção das relações sociais de gênero apresenta-se como um novo paradigma, capaz de não simplesmente visibilizar mulheres e/ou grupos oprimidos, como também iluminar as descobertas sobre a estruturação das opressões e dos jogos de poder que organizam os discursos normativos e estabelecem controles sociais [...], analisar gênero torna-se uma importante ferramenta teórica que ao enfrentar a pergunta pelas relações sociais de poder é capaz de articular não só a confluência das relações de sexo, mas também étnicas, de classe que permeiam as diversas parcelas da humanidade. (SAMPAIO, 2009, p. 128-129).
\end{abstract}

Portanto, o objetivo do presente artigo foi demonstrar a diferença entre as atividades de lazer vividas pelas mulheres e pelos homens trabalhadores das Cooperativas de Piracicaba-SP e as relações de gênero entremeadas nos principais conteúdos culturais do lazer que aparecem em suas práticas.

\title{
METODOLOGIA
}

A pesquisa foi de caráter qualitativo exploratória, tendo como metodologia utilizada uma combinação de pesquisa bibliográfica embora, no presente artigo, apenas parte dela tenha sido mencionada e pesquisa de campo. Posteriormente, para que fosse possível a identificação do perfil dos participantes, principalmente no que diz respeito à atividade preferida nas horas vagas, foi realizada uma pesquisa de campo por meio de questionário com questões abertas e fechadas (LÜDKE; ANDRÉ, 1986). 
Participaram 45 cooperados, sendo 26 homens e 19 mulheres participantes de quatro cooperativas de trabalho de Piracicaba-SP (Costureiras e Bordadeiras do Centro; Recicladores Solidários; Costureiras do Jardim Oriente; Guardadores de Carros Flanelinhas). As cooperativas em estudo constituíam-se por grupos mistos de homens e mulheres que tinham em comum a realidade da baixa renda e baixa escolaridade, com exceção da Cooperativa das Costureiras do Jardim Oriente que era composta somente por mulheres (TEJERA; SAMPAIO, 2007). Estas quatro cooperativas foram escolhidas pelo fato de terem sido subsidiadas pelo Projeto de Extensão Universitária, no período de agosto de 2004 a julho de 2005, denominado "Capacitação para processos cooperativos: projeto de subsídio às cooperativas criadas pelo FAE-UNIMEP”. O Projeto foi executado com o objetivo de proporcionar atividades de lazer para cooperados e cooperadas.

\section{RESULTADOS E DISCUSSÃO}

Durante o período vigente do projeto de extensão universitária, foi possível um convívio com as pessoas participantes de processos cooperativos, e percebeu-se que devido à baixa renda, grande parte das pessoas, entre homens e mulheres, complementava a renda através de "bicos", isso quando não tinham tarefas domésticas para cumprir, o que lhes tirava a possibilidade de ter tempo para o lazer em suas vidas.

As pessoas que informaram não ter tempo para as atividades, conforme respostas nos questionários se apoiaram no fato de ter de trabalhar fora, cuidar da casa e dos filhos, e cabe ressaltar, estas eram em sua maioria mulheres. A baixa renda que exige o “sobre-trabalho" é responsável não apenas por limitar o tempo livre das obrigações, mas implica que, a condição de ser mulher e mãe cria para elas um conjunto de 
impedimentos para vivenciarem o lazer. Em uma sociedade, que além de marcada pelo mercado capitalista é também patriarcal, a divisão do trabalho doméstico entre os membros da família é raridade e na maioria dos lares, a mulher, além de ter sua jornada de trabalho profissional, ao chegar a casa, assume as responsabilidades do lar. (MARCELLINO, 2002; SAMPAIO, 2008; BRUHNS, 1995).

Com a aplicação do questionário foi possível identificar quais eram os conteúdos culturais do lazer preferidos pelos homens e mulheres participantes das Cooperativas. Ao falarmos em conteúdos culturais, é importante lembrar que não é possível classificar a prática das pessoas, com apenas um denominado conteúdo. Embora haja uma determinada característica predominante, uma atividade é composta por vários aspectos, sem contar também que tal característica marcante em uma mesma atividade para uma pessoa, pode não ser a mesma para outra, dependendo do que essa pessoa busca enquanto vivência (MARCELLINO, 1983).

Tabela 1. Análise de frequência quanto às atividades preferidas das mulheres.

\begin{tabular}{c|c|c|c}
\hline Atividade Preferida & Frequência (\%) & Conteúdo Cultural & \% Total \\
\hline Sair com os filhos & 15,8 & Social & \\
Ir à Igreja & 10,5 & Social & \multirow{2}{*}{36,9} \\
Dançar & 5,3 & Social & \\
Ir à festas & 5,3 & Social & \\
Costura & 5,3 & Manual & 10,6 \\
Crochê & 5,3 & Manual & \\
Ler & 21,1 & Intelectual & 21,1 \\
Assistir TV & 10,5 & Artístico & 10,5 \\
Ginástica & 5,3 & Físico-esportivo & 5,3 \\
Descansar em casa & 5,3 & - & 15,8 \\
Nenhuma & 10,5 & - & \\
\hline
\end{tabular}

No caso das mulheres participantes da pesquisa, conforme expressa a (TAB.1), as atividades preferidas e seu mais próximo conteúdo cultural correspondente, foi 
apresentado por maiores incidências no conteúdo social para as opções de "sair com os filhos" com um destaque importante, seguido pela opção de "ir à igreja", enquanto que “dançar" e "ir à festas" aparecem uma vez, cada uma delas. Se somadas às escolhas pelo lazer de caráter social este predomina entre as mulheres. Na sequência, não com a mesma frequência, mas de modo significativo o ato de "ler" marca a dimensão intelectual, seguido pelo interesse artístico, expresso no "assistir televisão". O conteúdo manual, com atividades de costura e crochê e o físico-esportivo com ginástica aparecem poucas vezes. Três delas apresentam respostas que não se enquadram explicitamente em nenhum conteúdo, duas por não saberem o que responder e uma delas que aponta o “descanso em casa” como sua opção.

Chama à atenção a existência de pessoas que não sabem o que fazem em seu tempo livre das obrigações, talvez por não terem mesmo este tempo, ou pouco refletirem sobre o que fazem e simplesmente viverem o que aparece no cotidiano.

Tabela 2. Análise de frequência quanto às atividades preferidas dos homens.

\begin{tabular}{c|c|c|c}
\hline Atividade Preferida & Frequência (\%) & Conteúdo Cultural & \% Total \\
\hline Fliperama & 3,8 & Social & \\
Ir ao Pagode & 7,7 & Social & 26,9 \\
Ir à Igreja & 7,7 & Social & \\
Passear & 7,7 & Social & \\
Caminhada & 7,7 & Físico-esportivo & \\
Exercício Físico & 3,8 & Físico-esportivo & 30,7 \\
Jogar Futebol & 19,2 & Físico-esportivo & \\
Assistir TV & 23,1 & Artístico & 26,9 \\
Ouvir Música & 3,8 & Artístico & \\
Cozinhar & 3,8 & Manual & 3,8 \\
Ler & 7,7 & Intelectual & 7,7 \\
Nenhuma & 3,8 & - & 3,8 \\
\hline
\end{tabular}

Ao traçar um processo de análise, comparam-se as respostas dadas pelos homens participantes do mesmo processo cooperativo e percebem-se diferenças significativas. 
Sobressai com maior freqüência o conteúdo físico-esportivo, no caso o "jogar futebol" e aparecendo em menor escala o "exercício físico" e a "caminhada". Em igual proporção seguem os interesses sociais e artísticos, neste último, predominando a atividade de “assistir TV”. Já o conteúdo social foi marcado pelas opções de "ir ao pagode”, “à igreja", "passear" e "fliperama". Os demais conteúdos têm pequeno destaque em seus cotidianos, seguem o intelectual com "leitura", e o manual com "cozinhar" e um deles que não soube indicar nenhuma atividade de lazer.

Nos resultados obtidos pode-se observar um equilíbrio entre a opção pelo interesse social entre as mulheres e homens participantes da pesquisa. Contudo, neste aspecto, ao apontar a atividade "ir à igreja" ambos se igualam, assim como se aproximam ao indicar "ir ao pagode" pelos homens três vezes e uma vez entre as mulheres a opção "dançar". "Festas" aparecem uma vez entre as mulheres e "fliperama" uma vez entre os homens. Ressalta-se que no caso das mulheres "sair com os filhos" está indicado por elas como lazer e não aparece nada semelhante entre os homens. De alguma maneira, reforçando os processos culturais de gênero, em que os filhos são sempre filhos da mãe, poucas vezes os pais se ocupam deles no cotidiano, inclusive nos momentos de lazer (SAMPAIO, 2008; BRUHNS, 1995).

Possivelmente a ocorrência desse fato seja reflexo do processo de naturalização de que filhos devem estar aos cuidados das mães. Acredita-se que não é por acaso que isso acontece, e sim, devido à sociedade patriarcal em que vivemos, a qual "[...] investe muito na naturalização deste processo. Isto é, tentar fazer crer que a atribuição do espaço doméstico à mulher decorre de sua capacidade de ser mãe” (SAFFIOTI, 1987, p.9). Um processo de empoderamento diferenciado se pode perceber no cotidiano das mulheres que vão se distanciando da menina meiga, não por abandonar a ternura, mas 
para vivenciar seu lugar na poder na vida concreta como nos mostram os estudos de Petronilha Silva (1998) e de Raquel Gonçalves (2012).

Em contrapartida, no caso do interesse físico-esportivo, não se encontra a aproximação vista no conteúdo social. Ao contrário, temos uma relação extremamente inversa com oito homens afirmando ter afinidade com atividades físico-esportivas, predominando o "jogar futebol", enquanto entre as mulheres, apenas uma revelou ter gosto por esse tipo de vivência apontando a "ginástica" como atividade. Pode-se dizer que um dos principais motivos da incidência das opções dos homens por este conteúdo cultural vem principalmente da introdução do esporte com bola nas brincadeiras infantis dos meninos, tanto na rua como na escola, bem como a cultura introjetada de que o futebol semanal é fundamental aos homens como lazer. Uma construção social traçada tanto nos espaços escolares quanto nos espaços tradicionais das ruas (GOMES, 2012; LEITE, 2002).

No que concerne ao conteúdo artístico uma proporção de o dobro de homens para mulheres foram identificadas, isto é, três mulheres para sete homens indicam o "assistir televisão" como sua atividade de lazer, chamando a atenção para o fato de selecionarem uma atividade bastante passiva e pouco crítico-criativa. Os homens em frente à televisão apenas reforçam a perspectiva de que em casa o tempo livre das obrigações é muito mais possível aos homens do que às mulheres. A disponibilidade de tempo diferente entre ambos está diretamente relacionada às responsabilidades com tarefas de casa e cuidado dos filhos. Não resta dúvida de que a opção pela televisão como lazer também está fortemente associada à baixa renda desse grupo pesquisado, uma vez que esta é uma atividade que em si não demanda investimentos constantes 
superando restrições financeiras que outros tipos de lazer implicam (ROCHA e ROCHA, 2012).

No âmbito dos interesses intelectual e manual, há destaques importantes a fazer. O número de mulheres que aponta a leitura como lazer é superior aos homens, mais do que o dobro. Sendo esta atividade a segunda mais indicada pelas mulheres, vindo abaixo da opção pelo interesse social. No caso dos homens o conteúdo cultural intelectual, o ato de "ler" é inexpressivo em relação à grande freqüência de opções pelos interesses físico-esportivo, social e artístico. Curiosamente aparece como opção de lazer manual de um dos homens pesquisados a atividade de "cozinhar" como lazer e entre as mulheres as atividades que fazem em seu trabalho na Cooperativa o "costurar" e o "crochê".

Não apenas as presenças são alvo de análise, mas os silêncios também devem nos ocupar. Os interesses culturais do lazer acrescentados ao debate nos últimos anos por Camargo (1992) e Schwartz (2003), as vertentes turísticas e a virtual não compõem o universo das pessoas participantes das Cooperativas que participaram da pesquisa. Nenhuma delas mencionou nenhuma atividade que reporte a estes conteúdos, muito possivelmente porque não fazem parte de seu horizonte de pensamento e desejo imediato.

A distância destes bens culturais está profundamente relacionada com a realidade que marca a população estudada, pessoas de baixa renda e com uma necessidade de trabalhar muitas horas por dia para sobreviverem. Isso nos remete ao fato de que nossas discussões sobre lazer precisam além de perguntar pelas questões de gênero como se está fazendo, perguntar também pelas questões de classes sociais para 
não corrermos o risco de fazermos um tratamento alienado e universalizante do lazer que dista do cotidiano real de muitas pessoas concretas.

Independente da prática de quaisquer que sejam os conteúdos do lazer, o uso do tempo para homens e mulheres é efetivamente diferente devido a fatores culturais e sociais. Na maioria das vezes, essas diferenças já começam na infância, com os adultos impondo atividades do tipo competitivas e agressivas para os meninos e atividades delicadas para as meninas (SAMPAIO, 2008). Outro fator relevante na questão do tempo disponível para as mulheres é o fato de que na grande maioria das vezes elas assumem a maior parte das tarefas domésticas (MARCELLINO, 2002) e o cansaço pela dupla jornada de trabalho e o tempo de deslocamento para o mesmo tende a impactar negativamente sua disponibilidade de tempo para a prática de lazer (ROCHA e ROCHA, 2012).

Diante desses pressupostos, podemos perceber que a categoria de gênero proporciona muitas possibilidades de análise sobre os processos de naturalização das relações sociais (SCOTT, 1995; MORAES, 1998; SAMPAIO, 2008), cuja cristalização em situações próprias para homens ou para mulheres, precisa dar lugar a uma análise crítica dos poderes que estão em jogo quando uns se ocupam de algumas tarefas e diversões e outros não podem fazê-lo em iguais condições.

Se gênero é uma das barreiras a serem derrubadas para a vivência do lazer, não cabe dúvida que outras precisam ser enfrentadas como as barreiras de classe, de etnia, de idade, de crença para que a experiência das pessoas reinvente as relações de poder e seus processos de emancipação por meio do lazer.

Contudo, a partir dos estudos de gênero, articulados às condições étnicas, de classe ou idade (CRENSHAW, 2002; RADL, 2010; SAMPAIO, 2009), pode-se 
questionar profundamente as desigualdades que são praticadas e encobertas por um discurso calcado em justificativas biológicas “culturalizadas", as quais não são capazes de responder por todas as relações de poder que inferiorizam e excluem muitas pessoas por seu sexo, sua identidade de gênero, sua etnia, classe ou idade.

Considerando que as relações sociais de gênero se manifestam de várias formas e em diversas esferas da vida, seja no modo de conversar, falar, pensar, caminhar, dividir tarefas e oportunidades, escolher o tipo de lazer a ser vivenciado, entre outros, compreende-se que os estudos do Lazer não podem seguir sem um aprofundamento deste debate ora retomado.

A realidade desvendada pelos estudos que articulam gênero e lazer alia-se a outras discussões teóricas de cunho crítico e criativo visando refletir sobre possibilidades de mudança, que apesar de serem lentas e trabalhosas são necessárias em diversas esferas da vida. É importante lembrar que não está em questão acabar com as diferenças, mas sim, criar um ambiente onde pessoas diferentes possam ser igualmente respeitadas, tendo acessos iguais a direitos e deveres.

Acredita-se que a busca pela equidade entre gêneros é muito mais do que reconhecer o valor e o espaço das mulheres na sociedade em condições de igualdade ao dos homens, mas buscar a equidade implica ampliar a cultura humana vivenciando diversas experiências sem carregar o peso do preconceito e desconstruindo as amarras das masculinidades e feminilidades fixas e rígidas agarradas às inúmeras possibilidades de vivenciar o lazer.

\section{CONSIDERAÇÕES FINAIS}


A pesquisa identificou que as mulheres efetivamente têm mais dificuldade de desfrutar do tempo livre das obrigações do que os homens, devido à carga sócio-cultural que recebem, advinda de características genéticas diferenciadas que são tomadas como condições de desigualdades sociais. Um dado que em si não se manifesta como novidade, mas ressalta a importância de que a análise de gênero se constitua em parte da prática dos estudos aprofundados do lazer.

Os resultados evidenciaram que se na opção por atividades de interesses sociais homens e mulheres se aproximam na escolha geral, diferem na particularidade do que fazem, homens direcionam mais seu tempo em festas, as mulheres no "passeio com os filhos". Também a busca das mulheres por atividades intelectuais como a leitura está em proporção inversa a dos homens que se concentra em atividades físico-esportivas com predominância do "jogar futebol". O que mais os aproxima é o interesse artístico em que elegem o "assistir televisão" como seu momento de lazer. Revelando, nesses processos todos, marcas culturais que podem ser reinventadas.

Embora a principal intenção do lazer seja a autossatisfação de quem o pratica, ele também pode ser fonte de aprendizado e emancipação, ao mesmo tempo em que proporciona o prazer. Por este motivo pretende-se por meio dele, desvelar a importância de momentos em que as pessoas ao serem interrogadas sobre o que fazem em seu tempo livre das obrigações possam tomar consciência do lugar que ocupam nas relações de poder em sua casa, em seu trabalho e na sociedade em geral e reconheçam no lazer um direito inalienável que é seu, é de todo o cidadão e cidadã. Independente do tempo que o processo requer superar barreiras que geram exclusão e inferiorização entre as pessoas, é fundamental e o lazer muito pode contribuir para esta realidade. Este processo de empoderamento, iniciado pelo projeto de Extensão em alguns bairros de Piracicaba, foi 
possível perceber porque as comunidades formadas pelos cooperados e cooperadas seguiram nos anos subsequentes mantendo atividades de lazer como parte constitutiva de sua organização cooperativa.

\section{REFERÊNCIAS}

AUAD, Daniela. Feminismo: que história é essa? Rio de Janeiro: DP\&A, 2003.

BRUHNS, Heloisa Turini. Corpos femininos na relação com a cultura. In: ROMERO, Elaine (Org.). Corpo, Mulher e Sociedade. Campinas: Papirus, 1995.

CAMARGO, Luiz Octávio. O que é lazer. São Paulo: Brasiliense, 1992.

CRENSHAW, kimberlé. Documento para o encontro de especialistas em aspectos da discriminação racial relativos ao gênero. Revista de Estudos Feministas. v.10, n.1, p. 171-188, 2002.

DUMAZEDIER, Joffre. Valores e conteúdos culturais do lazer. São Paulo: SESC, 1980.

ELIAS, Norbert; DUNNING, Eric. A busca da excitação. Lisboa: Difusão Editorial, 1985.

GOMES, Dornelles Priscila. Do corpo que distingue meninos e meninas na educação física escolar. Cad. CEDES, 2012, v.32, n.87, p.187-198, 2012.

GONÇALVES, Salgado Raquel. Da menina meiga à heroína superpoderosa: infância, gênero e poder nas cenas da fícção e da vida. Cad. CEDES, v.32, n.86, p.117-136, 2012 .

LEITE, Maria Isabel Ferraz Pereira. Brincadeiras de menina na escola e na rua: reflexões da pesquisa no campo. Cad. CEDES, v.22, n.56, p.63-80, 2012.

LOURO, Guacira Lopes. Gênero, Sexualidade e Educação - Uma Perspectiva Pós Estruturalista. Petrópolis, Rio de Janeiro: Vozes, 1997.

LUDKE, Menga e ANDRÉ, Marli E.D.A. Pesquisa em educação: abordagens qualitativas. São Paulo: EPU, 1986.

MAGNANI, J. G. C. Lazer: Um campo interdisciplinar de pesquisa. In: BRUHNS, H. T.; GUTIERREZ, G. L. (Org.). O corpo e o lúdico: Ciclo de debates Lazer e Motricidade. Campinas: Autores Associados, 2000. p. 19-33.

MARCELLINO, Nelson Carvalho. Estudos do lazer: uma introdução. 3. ed. Campinas: Autores Associados, 2002.

. Lazer e humanização. Campinas: Papirus, 1983. 
MORAES, Maria Lygia Quartim de. Usos e limites da categoria gênero. In: Cadernos Pagu, n.11, 1998. p.99-105.

RADL, Philipp, Rita. Derechos humanos y género. Cad. CEDES, v.30, n.81, p.135155,2010

ROCHA, Ana Raquel; ROCHA, Angêla da. Consumidores da Base da Pirâmide e as restrições ao lazer. Revista Pensamento Contemporâneo em Administração. Rio de Janeiro, v. 6 , n. 2. Abr./jun. 2012.

SAFFIOTI, Heleieth I.B. O poder do macho. 12. ed. São Paulo: Moderna, 1987.

SAMPAIO, Tânia Mara V. A justiça social em perspectiva de gênero e raça. In: OLIVEIRA, Jose Lisboa Moreira de; SÍVERES,Luiz. (Org.). Ensaios sobre justiça social: refazendo o caminho da vida e da paz. Brasília: Editora Universa, 2009. p. 125146.

SAMPAIO, Tânia Mara Vieira. Gênero e Lazer: Um binômio instigante. In: MARCELliNO, Nelson Carvalho (Org.). Lazer e Sociedade, múltiplas relações. Campinas: Alínea, 2008.

SCHWARTZ, Gisele M. O conteúdo virtual do lazer: contemporizando Dumazedier. Revista Licere, v. 2, n.1, 2003.

SCOTT, Joan. W. Gênero: uma categoria útil de análise histórica. Educação \& Realidade, Porto Alegre, v.20, n.2, p.71-99, jul./dez. 1995.

SIEBERT, Raquel Stela de Sá. As relações de saber-poder sobre o corpo. IN: ROMERO, Elaine (Org.). Corpo, Mulher e Sociedade. Campinas: Papirus, 1995.

SILVA, Junior Vagner Pereira da; SOUSA, Ioranny Raquel Castro de; SAMPAIO, Tânia Mara Vieira. Acesso de Meninas e Meninos de Ceilândia - DF a Espaços Específicos de Lazer. CONGRESSO O LAZER EM DEBATE. UFMG Anais... 2012.

SILVA, Petronilha Beatriz Gonçalves e. "Chegou a hora de darmos a luz a nós mesmas": Situando-nos enquanto mulheres e negras. Cad. CEDES, 1998, v.19, n.45, p.7-23.

SOUSA, Eustáquia Salvadora de ;ALTMANN, Helena. Meninos e meninas: Expectativas corporais e implicações na educação física escolar. In: Cadernos Cedes. Ago.1999. p. 52-68.

TEJERA, Daniel Bidia Olmedo; SAMPAIO, Tânia Mara V. Buscando a compreensão da questão de gênero nas atividades de lazer em Cooperativas de Piracicaba. In: SILVA, Jamerson, A.A.; SILVA, Katharine, N.P. (Org.). Recreação, Esporte e Lazer - espaço tempo e atitude. Recife:Instituto Tempo Livre, 2007. v. 1, p. 363-368.

VIEIRA, Patrícia Rodrigues de Borba et al. Cães, mulheres e nogueiras, quanto mais se bate, melhor ficam. In: ROMERO, Elaine (Org.). Corpo, Mulher e Sociedade. Campinas: Papirus, 1995. 
Daniel B. Olmedo Tejera, Ioranny Raquel C. de Sousa, Tânia Mara V. Sampaio

\section{Endereço dos Autores:}

Daniel Bidia Olmedo Tejera

Universidade Estadual Paulista "Júlio de Mesquita Filho"

Instituto de Biociências

Departamento de Educação Física

Avenida 24-A, número 1515

CEP: 13506-900 - Rio Claro/SP

Endereço Eletrônico: olmedo@ig.com.br

Ioranny Raquel Castro de Sousa

Endereço Eletrônico: iorranyraquel@gmail.com

Tânia Mara Vieira Sampaio

Endereço Eletrônico: tsampaio@ucb.br 